\title{
Building resilience in contemporary nursing practice
}

Catherine Best Honorary Visiting Lecturer, Faculty of Health Studies, School of Nursing and Healthcare Leadership, University of Bradford

Email: a.c.best@bradford.ac.uk

\begin{abstract}
Resilience in nursing has been critiqued and challenged throughout the nursing literature. Trends in nursing have led to many nurses leaving the profession early in their career, often due to the immense pressures that they work under. There are many opinions on how nurses can develop the resilience needed to maintain professional integrity and continue to provide safe and effective care, while attempting to shoulder the considerable impact of political and professional drivers. This not only leaves nurses exhausted but often without hope. By taking collective action, this article argues that nurses may benefit from sharing ideas and learning from others, and in so doing rekindle hope and a belief that things can change.

Key words | Resilience | Compassion fatigue | Self-actualisation | Mindfulness | Transition
\end{abstract}

Resilience is a concept where people are encouraged to re-frame negative experiences or stressors so that they become a fundamental occasion for personal growth (Gill and Orgad, 2018). Central to this is the development of resilience and empowerment, both being attributes that can enable the individual to cope in stressful situations (Pines et al, 2017). Resilience has been extensively explored in the nursing literature and is considered an essential characteristic of nurses (Scammell, 2017; Kester and Wei, 2018). Physicians who report a greater level of career satisfaction are more likely to be associated with a greater level of patient satisfaction (DeVoe et al, 2007), while nurses who report increased levels of resilience are more inclined to report higher levels of patient care (Williams et al, 2016). Disappointingly, reports have told of catastrophic failings in healthcare, in which nurses have been implicated (Francis, 2013; Kirkup, 2015). The profession has come under scrutiny as the goal to fix nursing gains impetus (Strickland, 2018). This is no more evident than with the new pre-registration nursing standards (Nursing and Midwifery Council (NMC), 2018a) and the continued challenge to degree nursing status (Strickland, 2018). Despite these perceived failings and poor practices, many nurses have adopted a stoic approach and continue to tolerate working under immense pressure, often in conflicting and stressful environments. This situation, if allowed to continue, ultimately leads to burn out (Haik et al, 2017) and 'compassion fatigue' - which occurs as a result of the nurses' decreasing capacity to express empathy due to continual exposure to the suffering of others (Peters, 2018).

\section{Promoting mental health}

The NHS Staff and Learners' Mental Wellbeing Commission (Health Education England (HEE), 2019) reported that further research is needed into the causes of distress, fatigue, self-harm and suicide among health professionals, with female nurses and male paramedics 
in particular considered to be at significant risk. Regrettably, the stigma associated with poor mental health can create serious barriers to the access of quality care (Knaak et al, 2017).

The HEE (2019) commission considered the impact that poor mental health could have on maintaining positive health and wellbeing, and presented an ambitious plan to not only support people in times of adversity, but also in times of transition. Unfortunately, the work being undertaken is somewhat insufficient due to the failure to recognise the importance of social interactions in promoting resilience (Lee et al, 2015). There is also a failure to recognise the importance of nurse leaders educating more junior nurses on the importance of self-care (Kester and Wei, 2018) and in particular supporting self-actualisation (Maslow, 1943).

Nurses continue to live in a culture that prohibits the development of personal coping strategies and of a healthy and resilient nursing workforce. In order to ensure the health of nurses, argued Kester and Wei (2018), leaders must adopt new approaches to promoting the wellbeing of the nursing workforce, examples of which include the recognition of personal stressors, the provision of social support and the implementation of meaningful recognition, perhaps through awards or even tokens of gratitude. Developing a strategy that promotes mindfulness as a holistic intervention has the potential to benefit nurses' wellbeing (White, 2014).

\section{Mindfulness}

Having the ability to practise mindfulness, argued Cusack et al (2016), is an important step in helping nurses to step back from an emotionally charged situation, and in so doing create an opportunity for reflection, learning and moving forward. Several views commend the value of developing resilience through reflection (Kinman and Grant, 2011; McDonald et al, 2012). This requires gaining an understanding of another's suffering, being ready and willing to help, promoting wellbeing and enabling the sufferer to seek a solution to their problem (Perez-Bret et al, 2016).

However, developing resilience can be particularly challenging in nursing, a role in which uncertainty and the need for effective decision-making are constant (Scammell, 2017). Being able to effectively manage personal mental and physical health is as essential as caring for a patient's health (Lloyd and Campion, 2017). Mills et al (2015) advocated that the inability to demonstrate self-care, kindness and compassion to oneself has the potential to compromise and demonstrate compassion to others. The role of nursing is changing and the demand for nurses and the need to deliver care to patients with increasingly complex care needs is greater than ever (Cummings, 2016). Furthermore, as nurses move to new roles, in clinical and non-clinical environments, the transition that occurs can be particularly challenging as they begin to experience doubt, unfamiliarity and a sense of unease (Sellman, 2018).

\section{Transition}

The impact of transitioning from a student to registered nurse is extensively reviewed in the nursing literature, (Higgins et al, 2010; Blevins, 2018). Transitions begin very early in a career, including leaving school and going into further and then higher education and 
ultimately into a professional role (HEE, 2019). Transitioning positively necessitates an intrinsic understanding of oneself; self-care training and signposting to services as and when required can help to ensure periods of transition occur smoothly and effectively (HEE, 2019).

A recurring theme in the literature is the inability of student nurses to effectively transition to the role of registered nurse, as many find it challenging to fit into their new workplace environment (Laschinger et al, 2016). The experience of moving from pre-registration to registered nurse is often recognised as 'transition shock' (Duchsher, 2009) and is something that can cause many nurses to experience significant distress. Such transitions are often fraught with a wide-ranging and diverse range of emotions including anxiety, dread, emotional exhaustion and helplessness (Ebrahimi et al, 2016). For many nurses, this is a time when they can feel at their most vulnerable and experience feelings of insecurity and self-doubt as they adapt to the increasing responsibilities, leading to the 'imposter phenomena' also known as 'imposter syndrome' (Clance and Imes, 1978), although research indicates that nurses of all levels can experience this (Christenson et al, 2016). Imposter syndrome refers to highly successful individuals who are unable to recognise their achievements and have a constant fear of being uncovered or exposed as a fraud.

\section{Taking the lead}

New graduate nurses often encounter a significant period of stress (Waddell et al, 2015) and as a result they are leaving their initial employment at a disturbing rate (Cheng et al, 2014). The level of attrition in new graduate nurses, together with the rate of retirement of latecareer nurses, compound the problem of nurse shortages (Waddell et al, 2015). There have been significant changes to nurse education, including:

- The new pre-registration nursing standards (NMC, 2018a)

- The fast track Nurse First programme (NHS England, 2017)

- The nursing associate role (Darbyshire, 2018)

- Nursing apprenticeship programmes (Department of Health and Social Care, 2016)

- The changes to nursing bursaries, strongly lobbied for by the Council of Deans (Glasper, 2016).

Therefore, it could be argued that the nursing profession is in a significant phase of transition, with nurses doing their best to navigate the journey ahead. This requires nurses to adopt new approaches to managing the challenges. The nursing profession must step up and, through strong leadership, support its members in the nursing environment, whether clinical or non-clinical. This requires nursing leaders to promote positivity, become effective role models, encourage the sharing of positive experiences, capitalise on nurse's strengths and encourage self-care (Wei et al, 2019). Otherwise, it is likely that the future of nursing will remain uncertain.

\section{Challenges from within}

Nurses have been found to be able to furtively or openly direct their dissatisfaction towards each other and those deemed less powerful (Griffin, 2004), creating a situation called 'lateral violence' (Iheduru-Anderson, 2014). The future of nursing practice requires nurses, nurse managers, nurse educators both in further and higher education, clinical nurse educators and researchers to be cognisant of the importance of a resilient workforce that is able to meet the needs of service delivery and patient care. It requires the workforce to be 
part of the solution to ending lateral violence rather than being complicit in its problems (Egues and Leinung, 2013).

Furthermore, increasing challenges that threaten the nursing profession present a narrative through which nurses lose hope and leave. The reasons for this are complex, although Chan et al (2013) in their research on nurse shortages and intention to leave, highlighted two major factors: organisational and individual. Organisational factors are those that are directly related to the working environment and include workplace culture, professional demands, commitment of others, and the social support provided. Individual factors relate to those that directly impact the self and include demographic factors such as age, gender, education and marital status, personal job satisfaction and burnout, all of which can have a profound effect on intention to leave (Chan et al, 2013). Although Chan et al (2013) identified limitations to their research, they argued that nurse managers now have insight into the risks associated with nurses intention to leave. This knowledge empowers them to act to address the significant threat to nurse shortages and improve the quality of care. In order to limit this exodus, improving the emotional resilience of the nursing workforce is one argument, with individuals being expected to take more personal responsibility by adopting a resilient approach to their professional practice, irrespective of the challenges faced (Barratt, 2018). However, nurses should not be expected to shoulder every burden. The problem is part of a perpetuating global challenge, that of developing and maintaining a skilled workforce - one with the capability and aptitude to effectively manage the increasing pressures on the workforce (Jones and Sherwood, 2014).

However, simply focusing on the ability of individuals to manage increasing challenges and precarious situations, irrespective of the adversity, averts attention from the shared responsibility to safeguard individuals (Barrett, 2018). This means that failure to manage challenges is considered a failing by the individual, who has neglected to develop sufficient resilience, rather than considering the impact of social attitudes and public policy (Barrett, 2018; Gill and Orgad, 2018). Therefore, this leads to nurses being failed by the very people who should provide them with support - other nurses. This lack of support often leaves nurses in crisis and unable to recover sufficiently to return to everyday professional practice. A sad indictment when caring is considered a fundamental aspect of nursing (Warshawski et al, 2018).

\section{Conclusion}

Developing resilience among nurses has the potential to safeguard the health and wellbeing of the nursing population, sustain the workforce and ensure the provision of high-quality care (Barrett, 2018). Furthermore, building resilience can help students to thrive professionally and become able to face life events and challenges with a sense of hope and confidence, all while promoting enhanced wellbeing and long-term career sustainability (Stephens, 2013).

Being able to promote positivity means supporting nurses to see situations from a constructive and optimistic perspective. This approach has the capacity to facilitate social connections, which in turn can improve nurses' engagement and build positive relations with others, providing nurses with a healthy work environment and thereby improving resilience (Wei et al, 2018). 
The importance of ensuring effective transitions into new work roles has been explored, as has imposter syndrome, self-awareness, resilience and mindfulness. Just as we all have physical health, we also have mental health. It is important that we endeavour to achieve mental wellbeing (HEE, 2019), as we would physical health. It is normal that from time to time we will be firing on all cylinders, and at others we will not. Ensuring that one part of our life is working well often means that we can cope better when something goes slightly awry. So while facing these challenges, it is relevant to ask - who is caring for the carers?

Barratt C. Developing resilience: the role of nurses, healthcare teams and organisations. Nurs Stand. 2018;33(7):43-9. https://doi.org/10.7748/ns.2018.e11231

Blevins S. From nursing student to registered nurse: the challenge of transition. Medsurg Nursing. 2018;27(3):199-200

Chan ZC, Tam WS, Lung MKY, Wong WY, Chau CW. A systematic literature review of nurse shortage and the intention to leave. J Nurs Manag. 2013;21(4):605-13.

https://doi.org/10.1111/j.1365-2834.2012.01437.x

Cheng CY, Liou SR, Tsai HM, Chang CH. Job stress and job satisfaction among new graduate nurses during the first year of employment in Taiwan. Int J Nurs Pract. 2014;21(4):410-18. https://doi.org/10.1111/ijn.12281

Christensen M, Aubeeluck A, Fergusson D et al. Do student nurses experience Imposter Phenomenon? An international comparison of final year undergraduate nursing students readiness for registration. J Adv Nurs. 2016;72(11):2784-93.

https://doi.org/10.1111/jan.13034

Clance PR, Imes SA. The imposter phenomenon in high achieving women: dynamics and therapeutic intervention. Psychotherapy: Theory Res Pract. 1978;15(3): 241-7. https://psycnet.apa.org/doi/10.1037/h0086006

Cummings J. The role of nursing is changing - and demand is greater than ever. 2016. https://www.theguardian.com/healthcare-network/2016/feb/25/nurses-future-nhs-fiveyear-forward (accessed 10 July 2019)

Cusack L, Smith M, Hegney D et al. Exploring environmental factors in nursing workplaces that promote psychological resilience: constructing a unified theoretical model. Front Psychol. 2016;13(7):600. https://doi.org/10.3389/fpsyg.2016.00600

Darbyshire P. How not to argue against nursing associates. J Clin Nurs. 2018;27:7-8. https://doi.org/10.1111/jocn.14104

DeVoe J, Fryer GE Jr, Straub A, McCann J, Fairbrother G. Congruent satisfaction: is there geographic correlation between patient and physician satisfaction? Med Care.

2007;45(1):88-94. https://doi.org/10.1097/01.mlr.0000241048.85215.8b

Department of Health and Social Care. Nursing degree apprenticeship: factsheet. 2016. https://www.gov.uk/government/publications/nursing-degree-apprenticeshipsfactsheet/nursing-degree-apprenticeship-factsheet (accessed 10 July 2018) Duchscher JE. Transition shock: the initial stage of role adaptation for newly graduated registered nurses. J Adv Nurs. 2009;65(5):1103-13. https://doi.org/10.1111/j.13652648.2008.04898.x

Ebrahimi H, Hassankhani H, Negarandeh R, Gillespie M, Azizi A. Emotional support for new graduated nurses in clinical setting: a qualitative study. J Caring Sci. 2016;5(1):11-21. https://doi.org/10.15171/jcs.2016.002 
Egues AL, Leinung EZ. The bully within and without: strategies to address horizontal violence in nursing. Nurs Forum. 2013;48(3):185-90. https://doi.org/10.1111/nuf.12028

The London Stationary Trust. Report of the mid staffordshire nhs foundation trust public inquiry. 2013.

https://assets.publishing.service.gov.uk/government/uploads/system/uploads/attachment_ data/file/279124/0947.pdf (accessed 10 July 2019)

Glasper A. Funding nurse education in a climate of austerity. Br J Nurs. 2016;25(1):64-5. https://doi.org/10.12968/bjon.2016.25.1.64

Gill R, Orgad S. The amazing bounce-backable woman: resilience and the psychological turn in neoliberalism. Sociol Res Online. 2018;23(2):438-77

https://doi.org/10.1177\%2F1360780418769673

Griffin M. Teaching Cognitive Rehearsal as a Shield for Lateral Violence: An Intervention for Newly Licensed Nurses. J Contin Educ Nurs. 2004;35(6):257-63

Haik J, Brown S, Liran A et al. Burnout and compassion fatigue: prevalence and associations among Israeli burn clinicians. Neuropsychiatr.Dis Treat. 2017;13:1533-40.

https://doi.org/10.2147/NDT.S133181

Health Education England. NHS staff and learners' mental wellbeing commission. 2019.

https://www.hee.nhs.uk/sites/default/files/documents/NHS\%20\%28HEE\%29\%20-

\%20Mental\%20Wellbeing\%20Commission\%20Report.pdf (accessed 10 July 2019)

Higgins G, Spencer RL, Kane RA. A systematic review of the experiences and perceptions of the newly qualified nurse in the United Kingdom. Nurse Educ Today. 2010;30(6):499-508. https://doi.org/10.1016/j.nedt.2009.10.017

Iheduru-Anderson K. Educating senior nursing students to stop lateral violence in nursing.

Aust Nurs Midwifery J. 2014;22(1):15

Jones CB, Sherwood GD . The globalization of the nursing workforce: Pulling the pieces together Nurs Outlook. 2014;62(1):59-63. https://doi.org/10.1016/j.outlook.2013.12.005

Kester K, Wei H. Building nurse resilience. Nurs Manage 2018;49(6):42-5.

https://doi.org/10.1097/01.NUMA.0000533768.28005.36

Kinman G, Grant L. Exploring stress resilience in trainee social workers: the role of emotional and social competencies. Br J Soc Work. 2011;41(2):261-75.

https://doi.org/10.1093/bjsw/bcq088

Kirkup B. The Report of the Morecambe Bay Investigation. 2015.

https://assets.publishing.service.gov.uk/government/uploads/system/uploads/attachment_ data/file/408480/47487_MBI_Accessible_v0.1.pdf (accessed 10 July 2019)

Knaak S, Mantler E, Szeto A. Mental illness-related stigma in healthcare: barriers to access and care and evidence-based solutions. Healthc Manage Forum. 2017;30(2):111-116.

https://doi.org/10.1177/0840470416679413

Laschinger HK, Cummings G, Leiter $M$ et al. Starting out: A time-lagged study of new graduate nurses' transition to practice. Int J Nurs Stud. 2016;57:82-95

https://doi.org/10.1016/j.ijnurstu.2016.01.005

Lee KJ, Forbes ML, Lukasiewicz GJ et al. Promoting staff resilience in the pediatric intensive care unit. Am J Crit Care 2015;24(5):422-30. https://doi.org/10.4037/ajcc2015720

Lloyd C, Campion DP. Occupational stress and the importance of self-care and resilience: focus on veterinary nursing. Ir Vet J. 2017;70:30. https://doi.org/10.1186/s13620-017-01087

Maslow AH. A theory of human motivation. Psychol Rev. 1943;50(4):370-396.

https://psycnet.apa.org/doi/10.1037/h0054346 
McDonald G, Jackson D, Wilkes L, Vickers MH. A work-based educational intervention to support the development of personal resilience in nurses and midwives. Nurse Educ Today. 2012;32(4):378-84. https://doi.org/10.1016/j.nedt.2011.04.012

Mills J, Wand T, Fraser JA. On self-compassion and self-care in nursing: Selfish or essential for compassionate care? Int J Nurs Stud. 2015;52(4):791-3

https://doi.org/10.1016/j.ijnurstu.2014.10.009

NHS England. Next steps on the NHS Five Year Forward View: England's Chief Nurse announces 'Nurse First' to attract the best and brightest graduates to nursing. 2017. https://www.england.nhs.uk/2017/03/englands-chief-nurse-announces-nurse-first-toattract-the-best-and-brightest-graduates-to-nursing/ (accessed 10 July 2019) Nursing and Midwifery Council. Future nurse: standards of proficiency for registered nurses. 2018a. https://www.nmc.org.uk/globalassets/sitedocuments/education-standards/futurenurse-proficiencies.pdf (accessed 10 July 2019)

Nursing and Midwifery Council. The NMC Register. 2018b.

https://www.nmc.org.uk/registration/search-the-register/ (accessed 10 July 2019)

Perez-Bret E, Altisent R, Rocafort J. Definition of compassion in healthcare: a systematic literature review. Int J Palliat Nurs. 2016;22(12):599-606.

https://doi.org/10.12968/ijpn.2016.22.12.599

Peters E. Compassion fatigue in nursing: A concept analysis. Nurs Forum. 2018;53(4):466-

40. https://doi.org/10.1111/nuf.12274

Pines EW, Rauschhuber ML, Norgan GH et al. Stress resiliency, psychological empowerment and conflict management styles among baccalaureate nursing students. J Adv Nurs.

2017;68(7):1482-93. https://doi.org/10.1111/j.1365-2648.2011.05875.x

Scammell J. Resilience as part of nursing education: supporting nurses in times of austerity Br J Nurs. 2017;26(13):772. https://doi.org/10.12968/bjon.2017.26.13.772

Sellman D. From expert to novice: Shocking transitions in nursing. Nurs Philos.

2018;19(4):e12224. https://doi.org/10.1111/nup.12224

Stephens TM. Nursing student resilience: a concept clarification. Nurs Forum. 2013;48(2):125-33. https://doi.org/10.1111/nuf.12015

Strickland K. Nursing is battered and bruised: but now is the time to fight back. Br J Nurs. 2018;27(7):406-407. https://doi.org/10.12968/bjon.2018.27.7.406

Waddell J, Spalding K, Navarro J, Jancar S, Canizares G. Integrating a career planning and development program into the baccalaureate nursing curriculum. part ii. outcomes for new graduate nurses 12 months post-graduation. Int J Nurs Educ Scholarsh. 2015;12(1):175-82. https://doi.org/10.1515/ijnes-2015-0028

Warshawski S, Itzhaki M, Barnoy S. The associations between peer caring behaviors and social support to nurse students' caring perceptions. Nurse Educ Pract. 2018;31:88-94. https://doi.org/10.1016/j.nepr.2018.05.009

Wei H, Roberts P, Strickler J, Corbett RW. Nurse Leaders' strategies to foster nurse resilience. J Nurs Manag. 2019;27(4):1-7 https://doi.org/10.1111/jonm.12736

White L. Mindfulness in nursing: an evolutionary concept analysis. J Adv Nurs. 2014;70(2):282-94. https://doi.org/10.1111/jan.12182

Williams J, Hadjistavropoulos T, Ghandehari OO, Malloy DC, Hunter PV, Martin RR. Resilience and organisational empowerment among long-term care nurses: Effects on patient care and absenteeism. J Nurs Manag. 2016;24(3):300-8.

https://doi.org/10.1111/jonm.12311 